\title{
Case report: Weil's disease with multiple organ failure in a child living in dengue endemic area
}

\author{
Dewi Lokida 1,2, Arif Budiman', Udjiani Edi Pawitro' , M. Hussein Gasem³, Muhammad Karyana 3,4, \\ Herman Kosasih ${ }^{3^{*}}$ and Sophia Siddiqui ${ }^{5}$
}

\begin{abstract}
Background: There were few reports in the literature of Weil's disease with multiple organ failures, especially in children living in dengue endemic areas.

Case presentation: A 12-year-old child was admitted to Tangerang district hospital with a provisional diagnosis of dengue infection. On the third day of hospitalization, dengue diagnostic tests were negative. As fever still remained and was followed by jaundice, decreasing hemoglobin, increasing bilirubin with abnormal value of liver enzymes; other causes of disease were investigated. Leptospirosis was confirmed by rapid lgM test $\left(\mathrm{SD}^{\circledR}\right)$ for leptospira; and micro-agglutination test which indicated Leptospira serogroup bataviae infection. The patient developed Weil's disease during the course of illness. Renal function was back to normal on the 21 st day of hospitalization, while hemoglobin and bilirubin returned to normal three weeks after discharged.

Conclusions: Our report highlights the importance of considering leptospirosis as a differential diagnosis in children with acute febrile illness; even when the signs and symptoms for the more common diagnoses such as dengue or typhoid fever were pathognomonic. A normal leukocyte count with neutrophilia and negative dengue NS1, dengue IgM, and Salmonella typhi lgM on admission should raise suspicion of leptospirosis, and prompt diagnostic assays for leptospirosis should be conducted.
\end{abstract}

Keywords: Weil's disease, Leptospirosis, Children, Dengue

\section{Background}

Leptospirosis is a zoonosis caused by Leptospira interrogans complex [1]. Humans are infected through direct exposure to an infected animal, or indirectly via contaminated soil or water. Rattus norvegicus (brown rat) is the most important source of infection [1]. The clinical presentations range from subclinical to fatal (e.g.: Weil's disease) [1]. Severe cases are more frequent in adults than children $[2,3]$.

In Indonesia, leptospirosis was reported annually in 3-7 of its 34 provinces. The total number of cases increased from 335 in 2009 to 651 in 2013 [4]. As

\footnotetext{
*Correspondence: hermaninarespond@gmail.com

${ }^{3}$ Indonesia Research Partnership on Infectious Diseases (INA-RESPOND), Jakarta, Indonesia

Full list of author information is available at the end of the article
}

Indonesia is a populous country, these numbers may be under-estimated for several reasons. Firstly, leptospirosis is clinically undistinguishable from other infectious diseases, such as rickettsiosis, dengue, or typhoid fever, especially during the early stages of illness. Secondly, diagnostic tests are not easily available. Lastly, leptospirosis is often not considered, especially in children.

\section{Case presentation}

A 12-year-old boy presented to Tangerang district hospital, on 12 February 2015. Tangerang is a suburb in coastal area in the Jakarta metropolitan, consists of both agriculture and business areas. A large river crosses the middle of the town; and some areas are commonly flooded during the rainy season. Dengue and typhoid fever are endemic in this area; whereas sporadic outbreaks of 
influenza H5N1 have been reported since 2005 [5]. This boy had fever for three days $\left(38.0{ }^{\circ} \mathrm{C}\right.$, on admission to the hospital), headache, fatigue, and muscle pain. The patient was alert and anicteric, with blood pressure of $110 / 70 \mathrm{mmHg}$, pulse $100 \mathrm{~min}$, and respiratory rate (RR) of $22 \mathrm{~min}$. Complete blood count showed anemia $(7.5 \mathrm{mmol} / \mathrm{L})$, thrombocytopenia $(68,000 \mu \mathrm{L})$, neutrophilia (84\%), elevated absolute neutrophil count (ANC) $(6048 \mu \mathrm{L})$, and normal leukocyte count $(7200 \mu \mathrm{L})$. Based on these findings, a diagnosis of dengue hemorrhagic fever grade I was made; and the patient received supportive treatment with intravenous fluid, acetaminophen, and omeprazole.

On the third day of hospitalization, due to persistent fever, thrombocytopenia $(20,000 \mu \mathrm{L})$, leukocytosis $(15,000 \mu \mathrm{L})$, decreasing hemoglobin $(5.4 \mathrm{mmol} / \mathrm{L})$, and jaundice (total bilirubin/TB $82 \mu \mathrm{mol} / \mathrm{L}$ ); the clinical team conducted additional tests which were blood smear and Coomb's tests for Evans syndrome, dengue NS1 and IgM antibodies, HAV and HCV antibodies, HBsAg, and serum transaminases. All tests, except increased of AST $(371 \mathrm{U} / \mathrm{L})$ and ALT $(120 \mathrm{U} / \mathrm{L})$, were negative. On the fifth day of hospitalization, the patient appeared septic with oliguria, continued icterus, and RR of $26 / \mathrm{min}$. The clinicians requested rapid IgM test $\left(\mathrm{SD}^{\circledR}\right)$ for leptospira which came back positive. Biochemistry showed increased of TB $(366 \mu \mathrm{mol} / \mathrm{L})$, AST $(660 \mathrm{U} / \mathrm{L})$, ALT (179 U/L), BUN $(11.1 \mathrm{mmol} / \mathrm{L})$, and creatinine $(442 \mu \mathrm{mol} / \mathrm{L})$.

Leukocytosis and thrombocytopenia were persistent; and metamyelocytes were detected in blood smear. Blood cultures were negative. Interview with the family member revealed that the patient played in flood water near his house a week before illness. Treatment with ceftriaxone $70 \mathrm{mg} / \mathrm{kg}$ twice a day was commenced and continued for 14 days.

On the eighth day of hospitalization, the patient's renal function declined (BUN $20.35 \mathrm{mmol} / \mathrm{L}$, creatinine $503.8 \mu \mathrm{mol} / \mathrm{L}$ ); and he became anuric with decreased consciousness (Glasgow Coma Scale/GCS $=7$ ). While waiting for the availability of the intensive care unit (ICU) room for intubation, as required by the hospital standard procedure, the GCS improved in the following day. The patient was hemodialysed on the 10th and 12th day of hospitalization.

After hemodialysis, laboratory parameters began to improve; and on the 21st day of hospitalization, the patient was clinically improved and renal function became normal. The patient was discharged although he was still anemic (Hb $5.5 \mathrm{mmol} / \mathrm{L})$, had TB of $82.4 \mu \mathrm{mol} / \mathrm{L}$ and c-reactive protein (CRP) of $1.2 \mathrm{mg} / \mathrm{dL}$. His hemoglobin and bilirubin returned to normal three weeks after discharge.
With the parents' consent, serial plasma and serum were stored and later tested to confirm leptospira infection. Leptospira IgM rapid test $\left(\mathrm{SD}^{\circledR}\right)$ was positive in the samples on the first, fifth, and 20th day of hospitalization, and one week after discharge. The micro-agglutination test (MAT) assay was conducted in the leptospira reference center at Kariadi Hospital, Semarang on serum samples from the first, 10th, and 20th day of hospitalization. The titer for Leptospira serogroup bataviae increased from $<1: 20$ (on the first day and 10th day) to 1:640 (on the 20th day).

Retrospective tests on plasma samples during admission were negative for dengue NS1, dengue IgM, and Salmonella typhi IgM. However, several biochemistry parameters were slightly elevated, which were direct bilirubin $(13.7 \mu \mathrm{mol} / \mathrm{L})$, AST (123 U/L), ALT (53 U/L), BUN $(4.0 \mathrm{mmol} / \mathrm{L})$, creatinine $(123.8 \mu \mathrm{mol} / \mathrm{L})$, creatinin-kinase (CK) $(326 \mathrm{U} / \mathrm{L})$, CRP $(30.5 \mathrm{mg} / \mathrm{dL})$, amylase $(125 \mathrm{U} / \mathrm{L})$, and lipase $(98 \mathrm{U} / \mathrm{L})$. Serial hematology and biochemistry profiles are described in Fig. 1.

\section{Conclusions}

Our report highlights the importance of considering leptospirosis as a differential diagnosis in children with acute febrile illness; even though the signs and symptoms for more common diagnoses, such as dengue or typhoid fever, were pathognomonic. This case also highlights the need for considering disease specific tests as early as possible to confirm etiology. In case these tests were performed on the admission, a normal leukocyte count with neutrophilia; and negative dengue NS1, dengue IgM, and Salmonella typhi IgM should raise suspicion of other infections. This should lead to leptospirosis assays and a full hepatic panel examination.

Unlike in our case report, leptospirosis in children is often milder than in adults [2,3]. Our literature search only finds a few case reports of children with Weil's disease or severe leptospirosis [6-9], and none of them was from Indonesia. The involvement of multisystem organs was only reported in the two cases from Samoa and Srilanka [6,9]; whereas in two other cases, no liver involvement was detected $[7,8]$.

In our case, an early 2-3 times increase in transaminase, amylase, lipase, and CK on admission indicated hepatic and pancreatic involvement; and rhabdomyolysis. Neutrophilia, ANC, and thrombocytopenia on admission, followed by hemolytic anemia and the appearance of immature erythrocytes and increasing BUN and creatinine level on the second day, indicated hematological abnormalities and acute renal injury. Pulmonary involvement was evident by dyspnea and pleural effusion; and coagulation disorder was evident by increasing 


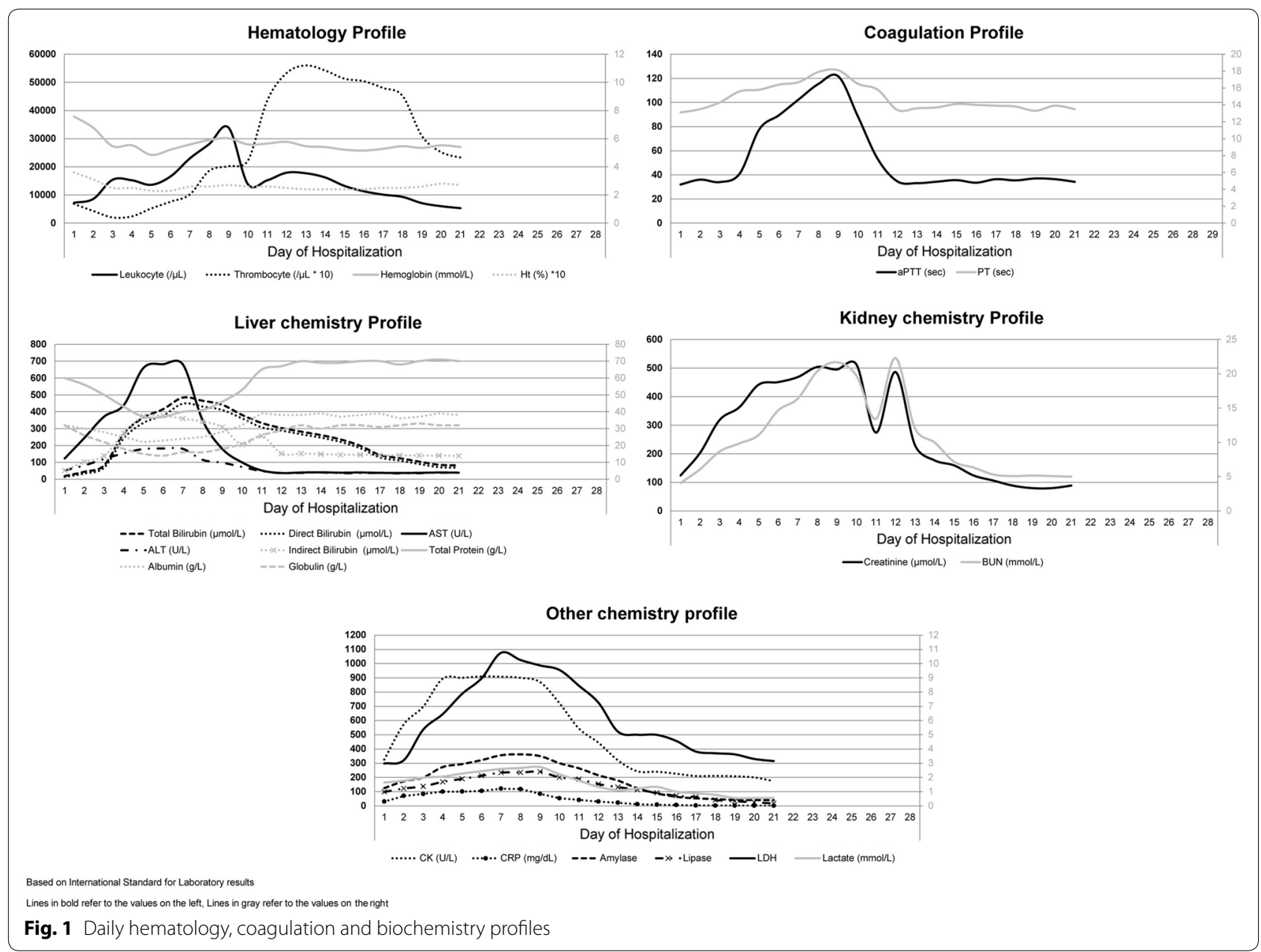

prothrombin time (PT) and an activated partial thromboplastin time (PTT) on the fifth day. Neurological involvement occurred on the eighth day of hospitalization when the patient was unconscious (GCS $=7$ ). Platelet was the first that returned to normal (on the eighth day), followed by PT, aPTT, and transaminase (on the 10-12th day).

The earlier recoveries of transaminase and persistent hyperbilirubinemia, which may last for more than five weeks [10], suggest that disruption of hepatocyte intercellular junctions is more severe than hepatocellular damage. The persistence of anemia might be associated with hemolytic uremic syndrome which occurs in rare cases of severe leptospirosis, probably as a result of the action of leptospiral toxins [11]; and/or the disturbance of erythropoietin production due to renal peritubular function impairment [1]. As this patient has no underlying diseases or comorbidities, we can only speculate that (1) the clinical severity was associated with the Batavia strain that was found in this patient, which might be as virulent as other strains that were previously reported (e.g.: strain icterohemorrhagica) [12]; and/or (2) the route of exposure (skin) and infectious dose were the risk factors for severity $[13,14]$; (3) severe leptospirosis is rare and therefore the asymptomatic infection and clinically mild cases are rarely confirmed or often misdiagnosed with dengue or salmonella infections [14]; (4) the severity was associated with the delay of the prompt treatment as it is well-documented that appropriate and early antibiotic treatment in leptospirosis cases leads to better disease outcomes [1].

Our report also highlights the importance of having accurate and early diagnostic tests for dengue infection to convince clinicians that when the results are negative, dengue infection can be excluded and other etiologies should be considered. The current dengue NS1 test is very specific for the first few days of fever; however, the sensitivity is low especially in endemic countries [15], whereas the IgM may only be accurate on the fifth day of illness [16].

Despite the detection of leptospira by using Leptospira IgM rapid test $\left(\mathrm{SD}^{\circledR}\right)$ in our case, this rapid test has not been validated. In addition, the confirmation test (MAT) 
can only be conducted at a reference laboratory, which are only available at two hospitals in Indonesia. Given the lack of reliable rapid tests and often unclear contact and exposure history, the findings of leukocytosis with a high $\mathrm{ANC}$, elevated $\mathrm{CK}$, and raised of hepatic and renal function parameters may suggest leptospirosis. Early diagnosis of leptospirosis would enable clinicians to start antibiotic treatment earlier, which is critical for reducing morbidity and mortality.

\section{Additional file}

Additional file 1. Dataset for the case report

\section{Authors' contributions}

$\mathrm{DL}$ conducted the laboratory testing, analyzing the data, drafted the manuscript, $A B$ analyzing the data, took care of the patient and review the manuscript, UEP took care of the patient and review the manuscript, MK analyzed the data and drafted the manuscript, MHG review the manuscript, HK analyzed the data and drafted the manuscript, SS analyzed the data and drafted the manuscript. All authors read and approved the final manuscript.

\section{Author details}

${ }^{1}$ Tangerang District Hospital, Tangerang, Indonesia. ${ }^{2}$ Kariadi Hospital, Semarang, Indonesia. ${ }^{3}$ Indonesia Research Partnership on Infectious Diseases (INA-RESPOND), Jakarta, Indonesia. ${ }^{4}$ National Institute of Health Research and Development (NIHRD), Jakarta, Indonesia. ${ }^{5}$ US, National Institute. of Allergy and Infectious Disease, Bethesda, USA.

\section{Acknowledgements}

We would like to thank our patient and his family for allowing us to share the data; to enhance the awareness of leptospirosis among clinicians, particularly pediatricians. We also thank nurses and laboratory technicians for collecting and testing the specimens. The preparation of this report was supported by Indonesia Research Partnership on Infectious Diseases (INA-RESPOND).

\section{Competing interests}

The authors declare that they have no competing interests.

\section{Availability of data and materials}

Data for this study is available as a additional document and can be downloaded through the link provided in the end of this manuscript (Additional file 1).

\section{Consent for publication}

Written informed consent was obtained from the parents of the patient for publication of this case report.

\section{Ethics approval and consent to participate}

The Ethics Committee of Tangerang Hospital granted the exemption for this study.
Received: 1 April 2016 Accepted: 6 August 2016

Published online: 15 August 2016

\section{References}

1. Haake DA, Levett PN. Leptospirosis in humans. Curr Top Microbiol Immunol. 2015;387:65-97.

2. Spichler A, Athanazio DA, Vilaca P, Seguro A, Vinetz J, Leake JA. Comparative analysis of severe pediatric and adult leptospirosis in Sao Paulo, Brazil. Am J Trop Med Hyg. 2012;86(2):306-8.

3. Daher EF, Vieira AP, Jacinto CN, Lima RS, Girao MM, Fernandes AT, et al. Differences among children, adolescents and adults with severe leptospirosis: a comparative analysis. Indian J Nephrol. 2014;24(3):166-70.

4. Bevan-Jones H, Miller DL. Bacterial meningitis, 1962-63. Mon Bull Minist Health Public Health Lab Serv. 1967;26:22-30.

5. Kandun IN, Wibisono H, Sedyaningsih ER, Yusharmen Hadisoedarsuno W, Purba W, et al. Three Indonesian clusters of H5N1 virus infection in 2005. N Engl J Med. 2006;355(21):2186-94.

6. Ranawaka N, Jeevagan $\mathrm{V}$, Karunanayake P, Jayasinghe S. Pancreatitis and myocarditis followed by pulmonary hemorrhage, a rare presentation of leptospirosis- a case report and literature survey. BMC Infect Dis. 2013;13:38

7. Othman N, Intan HI, Yip CW, Alias M, Amran F. Severe leptospirosis with unusual manifestation. J Trop Pediatr. 2007;53(1):55-8.

8. da Silva PS, Lipinski RW, Magalhaes RP, Romero EC. Severe acute renal failure in a child: a rare complication of anicteric leptospirosis. Pediatr Nephrol. 2007;22(11):1971-4.

9. Lau CL, DePasquale JM. Leptospirosis, diagnostic challenges, American Samoa. Emerg Infect Dis. 2012;18(12):2079-81.

10. Edwards CN, Nicholson GD, Hassell TA, Everard CO, Callender J. Leptospirosis in Barbados. A clinical study. West Indian Med J. 1990;39(1):27-34.

11. Faine S. Clinical leptospirosis in humans. In: Faine S, editor. Leptospira and leptospirosis. Florida: CRC Press; 1994.

12. Salamander B, Holzer E. Clinical aspects of Weil's disease (leptospirosis icterohemorrhagica). MMW Munch Med Wochenschr. 1978;120(20):703-6.

13. Mori M, Arimitsu Y, Otani S, Akama K. Intracutaneous infection with Leptospira icterohaemorrhagiae (Shibaura strain) of the guinea pig. Jpn J Med Sci Biol. 1974;27(6):297-308.

14. World Health Organization. Human leptospirosis: guidance for diagnosis, surveillance, and control. Geneva: World Health Organization; 2003.

15. Osorio L, Ramirez M, Bonelo A, Villar LA, Parra B. Comparison of the diagnostic accuracy of commercial NS1-based diagnostic tests for early dengue infection. Virol J. 2010;7:361

16. World Health Organization, SEARO. Comprehensive guidelines for prevention and control of dengue and dengue haemorrhagic fever. Geneva: World Health Organization; 2011.

Submit your next manuscript to BioMed Central and we will help you at every step:

- We accept pre-submission inquiries

- Our selector tool helps you to find the most relevant journal

- We provide round the clock customer support

- Convenient online submission

- Thorough peer review

- Inclusion in PubMed and all major indexing services

- Maximum visibility for your research

Submit your manuscript at www.biomedcentral com/submit 